MIT Case Studies in Social and Ethical Responsibilities of Computing • Winter 2022

\title{
Algorithmic Redistricting and Black Representation in US Elections
}

\section{Zachary Schutzman ${ }^{1}$}

${ }^{1}$ Institute for Data, Systems, and Society, MIT

License: Creative Commons Attribution-NonCommercial 4.0 International License (CC-BYNC 4.0). 


\section{ABSTRACT}

In the United States, the careful crafting of electoral districts has been a powerful tool for politicians to limit groups' political power or exclude them from representation entirely, most prominently to the detriment of political parties and racial and ethnic minority communities. Beginning in the 1960s, experts began proposing algorithmic solutions to the redistricting problem, in which a "neutral" computer program could draw "fair" districts free of human influence. Despite the traction that these proposals achieved both in academic and popular discourse, little work has been done to understand the extent to which algorithmically drawn districts do or do not comport with notions of fairness and equity. In this work, we perform such an analysis, running several proposed algorithms to generate districts in Alabama and Michigan. We observe that in both of these states, all four algorithms generate plans that provide fewer districts where Black voters would be expected to decide the outcome of the election, relative to both the proportion of Black people in their populaces as well as to the number of Black opportunity districts in the plans actually enacted by their state legislatures. We conclude with some discussion about the role of algorithms in redistricting moving forward, and how these tools might be used to enhance, rather than restrict, the ability for various communities to achieve elected representation.

Keywords: redistricting, algorithms, race, politics, elections

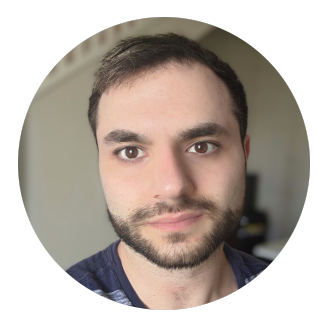

\section{Zachary Schutzman} Institute for Data, Systems, and Society, MIT

\section{Learning Objectives}

- Trace contemporary discourse and issues in redistricting to civil rights-era problems and responses.

- Identify arguments for and against the use of computerized algorithms in the redistricting context.

- Discuss similarities and differences between several redistricting algorithms.

- Interpret the output of these algorithms, in particular along the dimension of Black representation. 
The practice of gerrymandering, by which politicians intentionally manipulate the boundaries of electoral districts to help allies or hurt rivals who are trying to achieve political representation, is a practice as old as the United States itself. 1 Over the centuries, abuse of the redistricting process has been used to help or hurt political parties, racial and ethnic groups, and individual representatives in their quest for political representation in legislative bodies from the US Congress to local municipal and county governments. Drawing and redrawing maps of electoral districtsredistricting-became a tool with which members of various communities could be prevented from reliably electing their preferred candidates. Those electoral patterns, in turn, limited the ability of such communities to effectively lobby governments to respond to their interests; prevented representatives from these communities from ascending the political ranks; and, more generally, has run counter to the ideals of free and open democratic elections.

\section{Watch $\square$ : Landmark case of the United States Supreme Court concerning partisan gerrymandering} (2018)

\section{Visit the web version of this article to view interactive content.}

Listen Q: Rucho v. Common Cause Oral Argument

- 0:00/1:11:10

1)

Rucho v. Common Cause Oral Argument

Justices ruled that the Supreme Court can't set a constitutional standard to prevent partisan gerrymandering. Source: Supreme Court of the United States

Before the 1960s, states and localities had an enormous amount of leeway in how they designed and implemented districting plans, particularly state legislative districts, and through the 1940s, the Supreme Court affirmed this right. $\underline{2}$ Many states neglected to redistrict at all during the first half of the twentieth century, even as residents moved from rural regions to urban areas. According to Representative Morris Udall (D., Arizona), at the time the Supreme Court intervened in the early 1960s to demand that congressional and state legislative districts contain nearly equal numbers of people, 
there were some state legislative chambers where the largest district had hundreds or even thousands of times more voters than the smallest one. $\underline{3}$

Given this history of malapportionment, in the early 1960s advocates for "fair" redistricting began to propose the use of computer algorithms to generate districting plans. In 1961, economist William Vickrey proposed a framework in which an algorithm, given only the most basic data needed to draw districts that are geographically connected and balanced in population, could use opaque processes and randomness to separate the construction of districting plans from human influences entirely. ${ }^{4}$ Almost immediately after Vickrey's proposal, researchers and scientists designed theoretical and practical algorithms to achieve this, following a general framework of building algorithms to draw districts that maximized some notion of "compactness," a family of measures that describe the geometric regularity of a district, subject to the constraints of geographic connectedness and balanced population.

The foremost abuse that Vickrey and others sought to reform was the practice of allowing districts that were nowhere close to being equal in population; they urged instead that balanced populations be designed as a hard constraint within the new redistricting algorithms. However, despite these being very real and salient issues at the time, the case law that emerged in the early 1960s has created strong guardrails around population imbalance, and that kind of malapportionment is no longer a widely used technique to abuse the line-drawing process. Instead, the discussion of gerrymandering and unfairness in redistricting now revolves around racial and partisan inequities, preserving political units like municipalities and counties, and issues of incumbency. Despite these changes, the classical framework of algorithms, which optimize for compactness subject to population balance and geographic connectedness, still persists.

Every so often, an academic, politician, pundit, or concerned citizen will take to a social media platform to confidently assert that the only fair way to draw districting plans is via the use of a computer algorithm (Figure 1). 


\section{In order to combat the abuses of gerrymandering, the only fair thing to do is to use an algorithm to draw districts and take the power out of the politicians' hands.}

10:57 AM · Apr 12, 2021

\subsection{K Retweets 792 Quote Tweets $\quad$ 19.5K Likes}

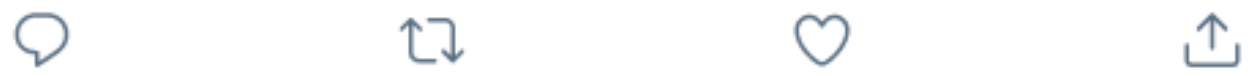

Figure 1

A fake tweet inspired by a real tweet.

Every time it comes up, this idea garners a good deal of enthusiastic support. People chime in with suggestions of what kinds of data the algorithm should and should not have access to, along with pictures of districting plans drawn using their personal favorite algorithm. However, what these well-meaning proposals often don't grapple with is the impact of using algorithmically drawn districts on the constituent communities in the jurisdiction. One such concern, which is the focus on this work, is that such plans systematically reduce the ability for Black voters to exercise sufficient political power to elect candidates of choice.

Arguments by today's proponents of algorithm-drawn districting plans generally fall under a few separate headings. The first, in the same vein as Vickrey's rationale, is that "fairness in redistricting" ought to be a descriptor of the process rather than the outcome. That is, a "fair districting plan" is one that results from a methodology for constructing those districts that adheres to generally acceptable principles, irrespective of the electoral outcomes resulting from those districts. As Vickrey argued in his 1961 article,

This means, in view of the subtle possibilities for favoritism, that the human element must be removed as completely as possible from the redistricting process. 
In part, this means that the process should be completely mechanical, so that once set up, there is no room at all for human choice. More than this, [...] it should not be possible to predict in any detail the outcome of the process. $\underline{5}$

Elements of this argument have been challenged from the computational perspective in previous work. $\underline{6}$ In brief, because communities with shared interests aren't geographically organized according to a mechanical process, there's no reason to expect a mechanical process to respect community structure or organization. Communities are structured according to natural boundaries like rivers and mountains, constructed boundaries like highways and state lines, and historical boundaries like segregation and discriminatory housing and lending practices (including "redlining"). $\stackrel{7}{ }$ All of these are challenging to describe in a redistricting process that is both amenable to computer implementation as well as free from "human choice."

The second argument acknowledges that algorithmic districting plans may lead to less than ideal outcomes, but posits that given the level of abuse in the current system-in which politicians and political actors design the redistricting maps-any departure from current practices (including algorithmic ones) will lead to better outcomes. Consider, for example, this recent comment on Twitter by a journalist who covers the US House of Representatives:

[Y]es, it's tough to reconcile algorithmic redistricting methods [with] the VRA [Voting Rights Act].

But don't underestimate the number of current maps that short-change opportunities for minorities [because] they over-pack minority voters into maj-min [majority-minority] VRA districts. $\underline{8}$

(As described following, the US Congress passed the Voting Rights Act in 1965, some provisions of which prohibit election practices that would systematically disenfranchise members of various racial or ethnic groups.) This case study challenges the argument that any computational approach to redistricting would yield improvements over present-day patterns. It is undeniable that many states, counties, and cities have abused (and continue to abuse) the power of the line-drawing process to systematically disempower and disenfranchise communities, in particular racial and ethnic communities. Yet we shouldn't accept without evidence the assertion that current distinct maps achieve less representation for the groups covered by the Voting Rights Act than those drawn by an algorithm. $\underline{9}$ 
More generally, advocates for algorithmic redistricting often argue that so-called neutral algorithms will generate districting plans that are "fair" if the algorithms do not incorporate specific kinds of data. For example, if algorithms do not include data such as the partisan composition of a region or the geographic distribution of people of various races or ethnic backgrounds, then (the argument goes) the algorithm cannot generate a plan that is unfair on a partisan or racial dimension. This argument, however, is unsupported by any mathematical or experimental evidence. Indeed, research has amply demonstrated in other computational contexts that simply omitting a variable from an algorithm or model does not guarantee that the output will be uncorrelated with that variable-because race and ethnicity are so often correlated with variables such as household income or residential neighborhood. $\underline{10}$ Indeed, our results show that various algorithm-generated districting plans clearly and consistently yield districting maps that weaken Black electoral opportunities compared with the enacted plans currently in use as well as with what a standard of proportionality might demand.

In this study we focus on the extent to which various algorithms proposed by researchers and experts do or do not draw plans that contain districts that allow Black voters the opportunity to elect candidates-of-choice, or opportunity districts. The study focuses on two US states with significant but geographically very different Black populations: Alabama and Michigan. Before diving into the computational results, it is important to define some terms and give some historical context for drawing opportunity districts for racial groups.

\section{“Opportunity Districts" and "Candidates of Choice"}

The notion of "opportunity districts" and how to draw them is complex, arising from a fusion of Supreme Court case law and federal civil rights legislation. In the mid-1950s,

amid the civil rights movement, the US Congress passed the Civil Rights Act of 1957.11 The provisions in this law made it much easier for Black citizens, particularly in southern states, to register to vote. In the wake of the 1957 law, the Alabama state legislature quickly moved to redefine the municipal boundaries of the city of Tuskegee, a square-shaped small city of about seven thousand people, approximately 80 percent of whom were Black. After redefining the boundaries, what remained of Tuskegee was a bizarre twenty-eight-sided figure with a population around fifteen hundred people, essentially all of whom were white; the state legislature had excised virtually all of the Black residents and exactly none of the white residents from the city. 


\section{Visit the web version of this article to view interactive content.}

\section{Gomillion v. Lightfoot Case Brief Summary \\ Privacy-enhanced mode enabled.}

In Gomillion v. Lightfoot (1960), the Supreme Court found that Alabama's legislature had acted specifically and intentionally to prevent Black voters from being able to participate in municipal government elections, and that the resulting disenfranchisement (via redefinition of municipal boundaries) was a violation of the Fifteenth Amendment. $\underline{12}$ This is generally considered to be the first court case on racial gerrymandering and was the first time the Supreme Court stepped in to limit a redistricting-like process. Preventing disenfranchisement via redefinition of electoral district lines was codified in the Voting Rights Act of 1965, with some clarification and updates in the amendments to that law passed in $1982 . \underline{13}$ Section 2 of the Voting Rights Act prohibits designing election laws, including the drawing of electoral districts, in such a way that members of a racial, ethnic, or language group "have less opportunity than other members of the electorate to participate in the political process and to elect representatives of their choice." Several court cases, a notable few including Beer v. US (1976), $\underline{14}$ Thornburg v. Gingles (1986), $\underline{15}$ the Shaw cases (1993, 1996, 1999, 2001) in North Carolina, $\underline{16}$ and Bush v. Vera (1996), $\underline{17}$ fleshed out mechanisms and limitations for identifying, challenging, and remediating racial gerrymandering.

There is a meaningful distinction between an opportunity district as defined by the Voting Rights Act and related case law, a so-called majority-minority district, and a district that reliably elects a member of a particular community as its representative. An opportunity district is simply one in which members of a particular community that votes cohesively can reliably decide who the elected individual will be. This group need not constitute anywhere near a majority in order to exercise this power (as in a majority-minority district), nor does the elected representative need to be a member of that community.

In many districts, party primaries are competitive, whereas general elections are not. For example, in a district that reliably votes 60 percent Democratic and 40 percent Republican in general elections, the Democratic primary often serves as the de facto contest that decides the general election result. If such a district is a region in which Black voters vote cohesively, then constituting a majority of the Democratic primary electorate is sufficient to give them the power to elect a candidate of choice, even 
while the district as a whole may only be 35 percent Black. For example, white Democrats in Detroit, Michigan, reliably support the candidate who wins the Democratic primary, so a Black opportunity district is one in which Black voters, acting cohesively, have the political power to decide the results of the Democratic primary in that district.

Candidate of choice is not synonymous with a candidate who happens to be a member of a particular racial or ethnic group. The issue at hand is whether members of some group have the level of political efficacy to influence district elections, not whether the elected representative from the district comes from any particular demographic group. In many cases, racial, ethnic, and language groups' candidate of choice is a member of that particular group, but not always. For example, Steve Cohen, a white Democrat, represents a solidly Democratic congressional district in Memphis, Tennessee, which is about two-thirds Black; Cohen has consistently won primaries in his district by overwhelming margins.

Even with sixty years of work designing and implementing redistricting algorithms, little attention has been paid to examining and comparing the districting plans that various algorithms generate along dimensions such as how well the resulting maps afford various communities the ability to elect their candidate of choice. $\underline{18}$ In this work, we compare the outputs from four recently proposed redistricting algorithms and evaluate the impacts that each algorithm would have on the distribution of Black opportunity districts in Alabama and Michigan.

\section{Data}

Each algorithm draws connected population-balanced districts composed of census blocks. In order to run the algorithms themselves, we only need some publicly available data from the US Census Bureau, which provides files containing both the geography of the census blocks as well as demographic data for each block. $\underline{19}$ This demographic data includes the total population of each block; the Black population of each block; and the Black population over the voting age of eighteen. The block geography and demographics come from the 2010 decennial census data, which was used as the official redistricting data prior to the recent release of the 2020 census data. $\underline{20}$

We consider two states, Alabama and Michigan, and use the algorithms to draw state senate districts for each state. According to the 2010 data, Alabama has a population around 4.73 million people and is 27 percent Black. The state has thirty-five state 
senate districts with approximately 136,000 people per district. Figure 2a shows the geographic distribution of Black people in Alabama. The cities of Birmingham and Montgomery in the center of the state and Mobile in the southwest are majority-Black cities of approximately 200,000 people each. The wide strip across the center of the state, sometimes called the "Black Belt," contains Montgomery as well as many smaller predominantly Black cities and a large rural Black population. In aggregate, this region is over 50 percent Black.

The 2010 population of Michigan is approximately 9.93 million and is 14 percent Black. The state has thirty-eight state senate districts, each containing around 260,000 people. Figure $2 \mathrm{~b}$ shows the geographic distribution of Black people in Michigan. In stark contrast to Alabama, the Black population is overwhelmingly concentrated in and around the city of Detroit, in the southeast part of the state. Wayne County, which includes Detroit, has a total population of roughly 1.8 million people, 33 percent of whom are Black. There is a sizeable Black community in the city of Flint in the center of the state, but the population is relatively small compared to that of Detroit, where approximately 80,000 of the 420,000 residents of Genesee County are Black. The remainder of the state is overwhelmingly white. 


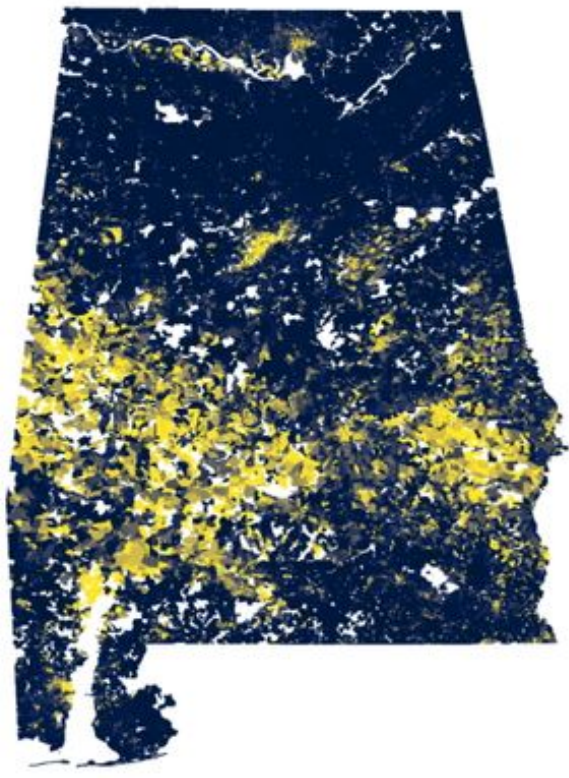

a

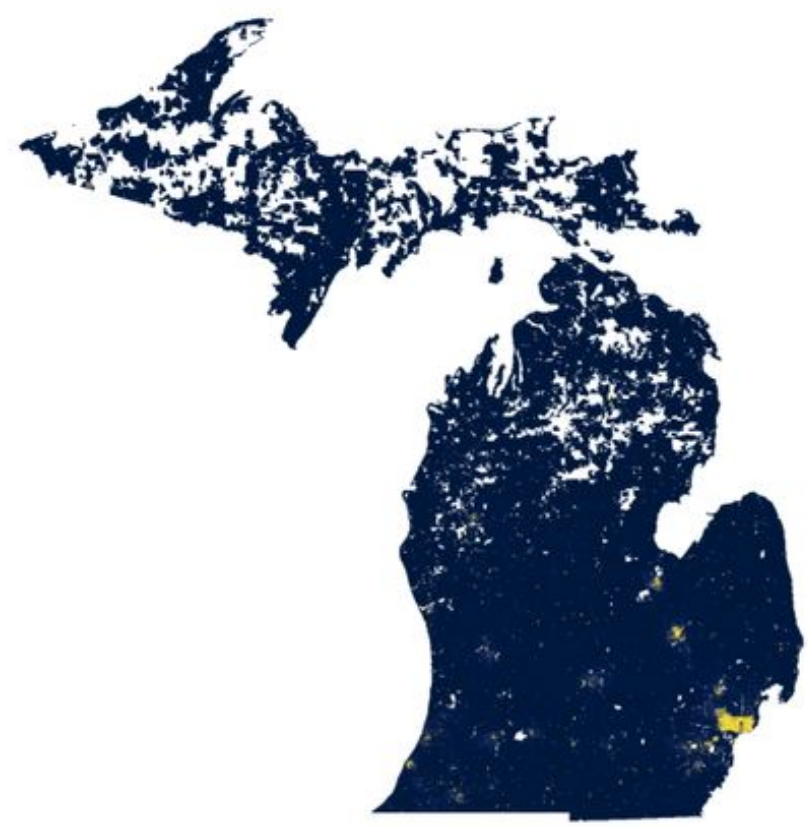

b

\section{Figure 2}

The Black population distributions for Alabama (a) and Michigan (b). The lighter, yellow regions have more Black residents.

This analysis considers redistricting plans for state senate rather than the more widely discussed US congressional districts in order to generate a richer set of outcomes. For instance, according to the 2010 reapportionment, Alabama is afforded seven members in the US House of Representatives. Its current districting plan includes one Black opportunity district, and experts and stakeholders have argued and sued for the state to redraw the plan to include a second. The algorithms typically generate zero or one Black opportunity districts for US congressional elections (and, on rare occasions, two). In contrast, the enacted state senate plan includes eight Black opportunity districts, and drawing as many as eleven or twelve may be possible. Working at the level of state senate districts therefore allows for a wider range of possible outcomes, and hence a more careful analysis of the behavior of the algorithms.

In Alabama, while there is a small portion of white voters who might reliably support the Black-preferred candidate, white voters in Alabama overwhelmingly support Republicans. Experts estimated this level of white support for Black-preferred candidates in the center of the state to be approximately 17 percent. $\underline{21}$ Therefore, whereas a district need not be strictly majority Black in order to reliably elect the 
Black voters' candidate of choice, it must come close. More precisely, we may define a "Black opportunity district" within Alabama to be one in which 95 percent of the Black voting-age population, together with 17 percent of the white population, constitute a clear majority in the district.

Unlike Alabama, Michigan includes a much larger proportion of white voters who typically vote for the Democratic Party. Estimates based on the 2016 US presidential election and the 2018 US Senate election in Michigan place the proportion of white Democrats around 45 percent. For this reason, if Black voters' candidate-of-choice wins the Democratic primary in a reliably Democratic district, we can expect white Democrats to support this candidate in the general election. In this case, the strength of Black voters in the primary determines whether a district is or is not a Black opportunity district. In Michigan, we use election data to estimate the partisan lean of a district, and we consider one to be a "Black opportunity district" if it both reliably will elect a Democratic candidate in the general election and Black voters constitute a majority of the estimated Democratic primary electorate. $\underline{22}$

\section{Algorithms}

In this section we briefly describe the four algorithms under consideration. At a high level, each of these algorithms is designed to take as input a collection of geographic units, such as census blocks, each equipped with a total population. They then solve a geometric optimization problem to draw districts that are connected, nearly equal in population, and as compact as possible, where the definition of compactness is either explicitly or implicitly encoded in the objective of the optimization problem.

Annealing. The first algorithm, which we call Annealing, was designed by a software engineer and its source code is available publicly online. $\underline{23}$ It is well-discussed in public discourse, having featured in a Washington Post article and used in FiveThirtyEight's Atlas of Redistricting project. $\underline{24}$ The algorithm works by choosing random district centers and assigning each census block to its closest center. Districts that are underpopulated incorporate the nearest blocks from districts that are overpopulated, and then the centers are recomputed. This annealing process of grabbing blocks repeats until the districts are population-balanced. The entire process, starting from new random centers, is repeated numerous times, and the plan that generates the most compact districts is returned as the final output.

Arcs. We call the second algorithm Arcs due to its unique characteristic of drawing districts bounded by circular arcs. This algorithm appears in a recent paper, and 
although its authors drew inspiration and lessons from several existing algorithms, the resulting districts are highly unlike those of any other algorithm. $\underline{25}$ To draw $k$ districts, the algorithm works by selecting a corner of the bounding box of the state and drawing the circular arc centered there which splits the state into two pieces which support $\left\lceil\frac{k}{2}\right\rceil$ and $\left\lfloor\frac{k}{2}\right\rfloor$ districts, respectively. (Here $\left\lceil\frac{k}{2}\right\rceil$ is the "ceiling," meaning the smallest integer greater than or equal to $k / 2$, whereas $\left\lfloor\frac{k}{2}\right\rfloor$ is the "floor," that is, the largest integer less than or equal to $k / 2$.) Then the algorithm is run recursively on each half, selecting a corner of the bounding box for each. The sequence of bounding box corners that is ultimately selected is the one that maximizes the compactness of the districting plan.

Voronoi. Algorithms using Voronoi diagrams and related procedures to generate districting plans have been proposed since at least the mid-2000s. We consider the most recent iteration in this line of work, which uses a generalization of Voronoi diagrams called power diagrams to partition a state into districts. $\underline{26}$ The algorithm to draw $k$ districts works as follows: It begins by selecting $k$ random points $c_{1}, \ldots, c_{k}$ to serve as the initial centers of the districts, and initializes an associated radius $r_{1}, \ldots, r_{k}$ to each one. We can then imagine $k$ circles, each centered at $c_{i}$ with radius $r_{i}$. We imagine the set of census blocks as little regions in an $x-y$ plane and feed to the algorithm a representation of each census block as the single point at its geographic center, to which we associate that block's population. Every one of these points is some distance from the boundary of every one of these circles, and the algorithm assigns each block to belong to the district corresponding to the closest of these circles.

There is no guarantee that these proto-districts will be anywhere close to populationbalanced, so the algorithm next performs an adjustment procedure, until the proposed set of districts becomes population-balanced. First the algorithm recomputes the centers $c_{1}, \ldots, c_{k}$ to be the centers of their respective proto-districts and leaves the radii $r_{i}$ alone. Then it assigns each block to the center whose circle's boundary is the nearest. Next it adjusts the radii while leaving the centers fixed. By solving an optimization problem, the algorithm can shrink or grow the radius of each protodistrict's circle to shrink or grow the population assigned to it.

Eventually, this algorithm will converge to a set of centers $C_{i}$ and radii $r_{i}$ that identify a collection of population-balanced districts. When thought of as collections of points, these districts are polygons, bounded by straight line segments. The algorithm also takes into account the geometry of these districts, such as the number of sides of any one of these polygons not being too large, and requiring every polygon to be convex except at the border of the state. When these assignments are mapped back onto 
census blocks, the boundaries become uneven, because census blocks do not follow perfectly straight lines. Due to the generally small size of census blocks, however, the districts may appear to have straight-line borders until one zooms in to a finer resolution.

Tree. The final algorithm we consider is a highly randomized one that appears in the software package GerryChain, a suite of algorithms used to generate large ensembles of districting plans with which one may compare a proposed or enacted plan. $\underline{27}$ Whereas the Voronoi algorithm conceptualized a state's census blocks as a collection of points, the Tree algorithm treats census blocks as components of a graph. Each census block becomes a vertex in this graph, with an edge between two vertices if and only if the vertices' corresponding census blocks share a geographic boundary. Each block's population is associated to its respective vertex. Whereas in the Voronoi algorithm the coordinate representation of the blocks was crucial information used by the computer to assign each block to the closest district center, the Tree algorithm discards such that geometric information and works with the graph representation.

The algorithm first constructs a random spanning tree of this graph. This can be thought of as a subcollection of the graph's edges for which restricting our view to the original set of vertices and this smaller set of edges results in a graph that is connected and contains no cycles. A crucial feature is that deleting any single edge from a spanning tree separates it into two connected components.

Once the algorithm has drawn a random spanning tree, it searches for an edge that, when removed, divides the vertices into a component which has the correct population for a single district and a component that has the correct population for $k$ - 1 districts. If the algorithm can identify such an edge, it performs this separation and freezes the smaller component as the first district. If it cannot identify such an edge, the spanning tree is discarded and a new one constructed.

The algorithm then proceeds recursively on the larger section and ignores what has already been frozen. After freezing the first district, it draws a random spanning tree and searches for an edge that, when removed, separates the component of interest into a district-sized piece and a piece with population appropriate for $k$ - 2 districts. This procedure continues until the algorithm has frozen all $k$ districts, and this becomes the output plan.

The districts drawn by this procedure tend to look more "organic" than those drawn by the other algorithms. This arises in part from the fact that the Tree algorithm does not 
incorporate the shape of the state or the geographic distances between blocks. Formal statements about the kinds of districts that this algorithm draws are difficult to make, but we can observe that generally it tends toward drawing districts that have many possible spanning trees underlying them. $\underline{28}$ This in turn means that we should expect the graph representation of the constituent districts to contain many cycles. This is potentially an attractive property, because the kinds of districts whose graphs contain very few cycles are ones with spindly tendrils extending in disparate directions. $\underline{29}$

\section{Results}

Alabama. Figure 3 shows the presently enacted districts for Alabama as well as the algorithmically generated plans. We can see that visually all of these plans are quite distinct, reflecting the differences in specification between the algorithms. Using the benchmark of 95 percent of Black voting-age population plus 17 percent of white voting-age population exceeding 50 percent, we can examine how many Black opportunity districts appear in each plan, the geographic location of these districts, and how reliably they could be expected to elect Black voters' candidate-of-choice (Figure 4).

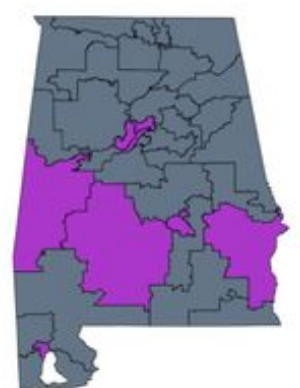

a. Enacted

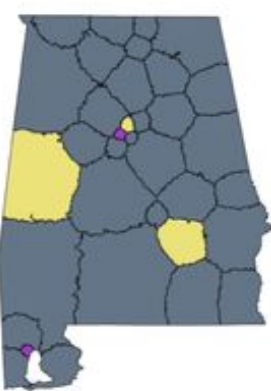

b. Annealing

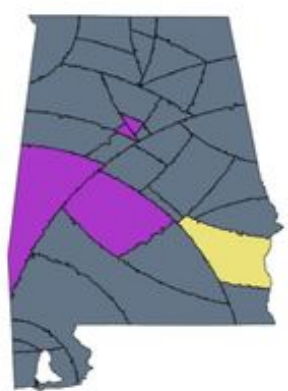

c. Arcs

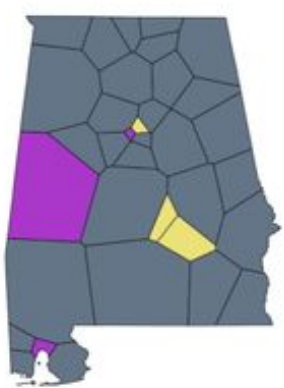

d. Voronoi

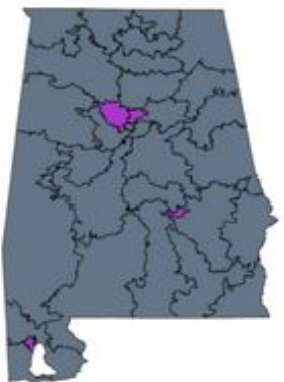

e. Tree

Figure 3

The enacted state senate districts in Alabama and the four algorithmically generated plans. Pink districts have at least 55 percent expected support for the

Black-preferred candidate; yellow districts have between 50 and 55 percent expected support. (a) The currently enacted state senate districts as of 2020. (b) Output from the "Annealing" algorithm. (c) Output from the "Arcs" algorithm. (d)

Output from the "Voronoi" algorithm. (e) Output from the "Tree" algorithm. 


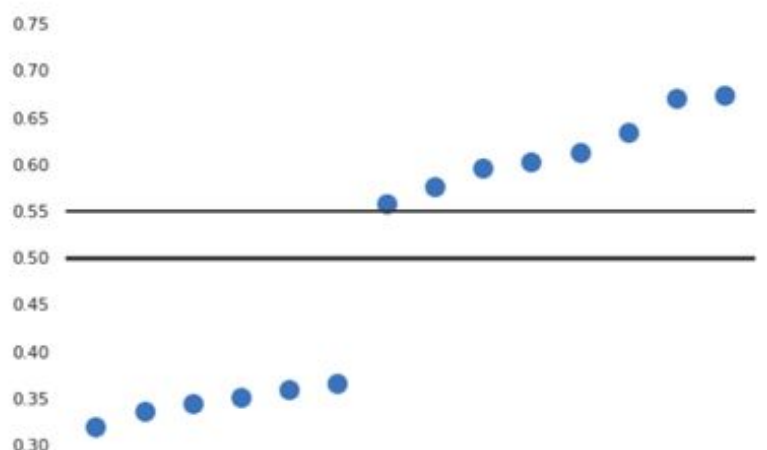

a. Enacted

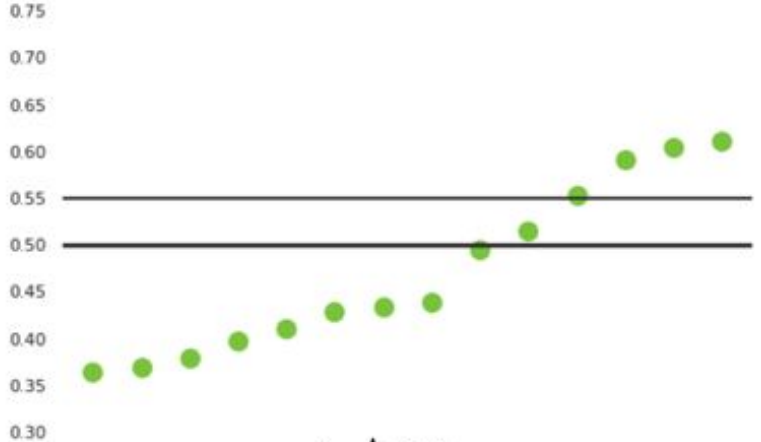

c. Arcs

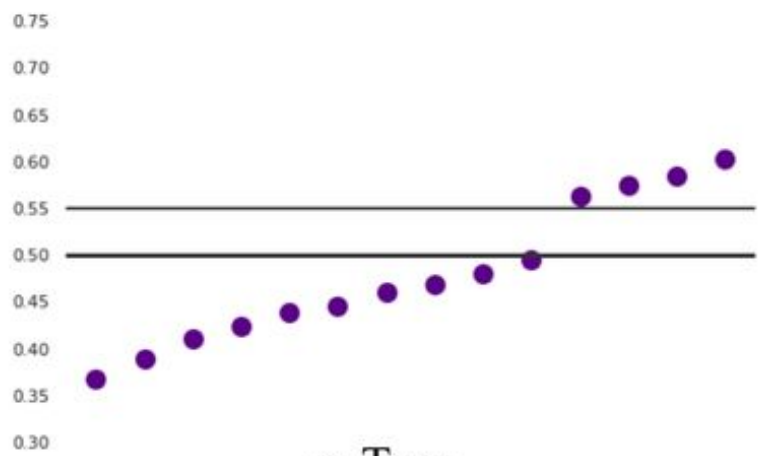

e. Tree

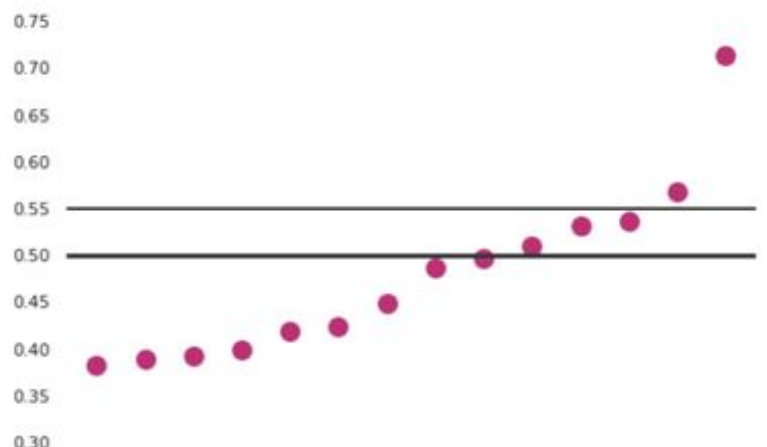

b. Annealing

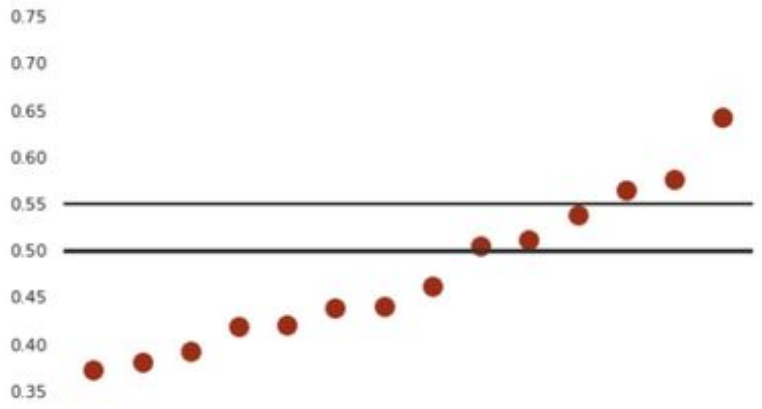

\section{d. Voronoi}

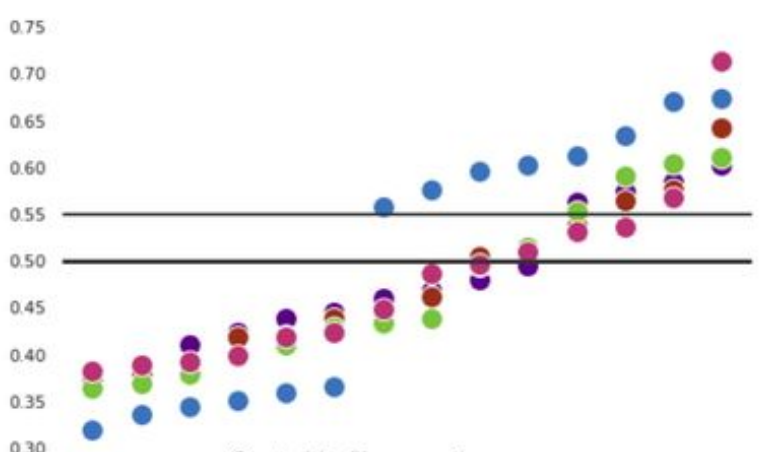

f. All five plans

Figure 4

Plots of the expected support for the Black-preferred candidate in the fourteen Alabama districts that have the largest Black populations. Sorted districts appear along the horizontal axis, and expected fraction of votes for the Black-preferred candidate appears along the vertical axis. (a) The currently enacted state senate districts as of 2020. (b) Output from the "Annealing" algorithm. (c) Output from the "Arcs" algorithm. (d) Output from the "Voronoi" algorithm. (e) Output from the "Tree" algorithm. (f) All five plots superimposed.

In the enacted plan (Figure 3a and Figure 4a), there are eight districts in which the expected support for Black voters' preferred candidate exceeds 50 percent. Three of 
these districts are anchored in Birmingham, one each in Mobile and Montgomery, and three across the more rural central region of the state. We can plot the expected support for the Black-preferred candidate in these eight districts as well as the four districts with next-largest Black population, and observe a clear demarcation between these eight and the next four (as well as the remaining twenty-three districts, not shown): the eighth district has over 55 percent expected support for the Blackpreferred candidate, whereas the ninth district has well below 40 percent expected support.

In the Annealing plan (Figure 3b and Figure 4b), we see a stark difference. This plan contains only two districts with expected support for the Black-preferred candidate over 55 percent, and an additional three districts in which the expected support falls between 50 and 55 percent. These five districts include two in Birmingham, one in Mobile, one on the periphery of Montgomery, and one large rural one in the west, and it is straightforward to see how this plan "misses" several of the opportunity districts in the enacted plan.

Plotting the expected support from the twelve districts with the highest Black population, we can see that the dramatic gap between the eighth and ninth districts in the enacted plan does not appear in the Annealing plan. Rather, there is a more gradual decline in expected support for the Black-preferred candidate from the second district downward. Relative to the enacted plan, the high-support districts underperform and the low-support districts overperform, suggesting that this plan would significantly dilute Black voting strength.

For the Arcs plan (ㅍguㅏㄹ $3 \mathrm{c}$ and Figure 4c), we see something similar. This algorithm again draws five potential opportunity districts, with four expected to fall above 55 percent support for the Black-preferred candidate and one in the intermediate range of 50 to 55 percent. This algorithm finds different opportunity districts than the ones identified by the Annealing algorithm. Here we have again two around Birmingham and one rural one in the west, but two additional large rural districts in the middle of the state.

Once again, we can examine the plot of expected support for the Black-preferred candidate by district, and again we observe a steady decline in expected supportmore like the Annealing plan than the abrupt gap present in the enacted plan. This finding suggests that the Arcs plan, like the Annealing one, would dilute Black voting strength compared to the current districting arrangement. The Voronoi plan (Figure $3 \mathrm{~d}$ and Figure 4d) performs similarly to the Annealing plan, but with an extra district in 
the 50 to 55 percent range around Montgomery and slightly greater expected support for the Black-preferred candidate in the rural district in the west. As for the previous algorithms, the plot of expected support indicates dilution of Black voting power.

The Tree algorithm draws a plan (igiure $3 \mathrm{e}$ and Figure $4 \mathrm{e}$ ) with four districts above the 55 percent expected-support level and none in the 50 to 55 percent range, which is a departure from the previous outputs. It also does not draw any rural opportunity districts, identifying only two such districts in Birmingham and one each in Montgomery and Mobile. Plotting the expected support level shows, however, that the effects of this plan are not very different from the other three algorithmic ones; it, too, features a steady decline in expected support, with a small gap between the fourth and fifth districts. However, we still see districts falling just below the 50 percent line, indicating that Black voters in these districts might be narrowly shut out of political power-an outcome of vote dilution common in each of these algorithmically generated plans.

Michigan. As for Alabama, the four algorithmic plans generate district maps for Michigan that are visually distinct from each other and from the enacted plan, which was designed in part to follow the rectangular county boundaries of the state. As noted above, Michigan does not have the same level of racially polarized voting as Alabama in the general electorate, which is reflected in the determination of Black opportunity districts. In Michigan, approximately 90 percent of Black voters and 45 percent of white voters supported Democratic Party candidates in recent statewide general elections. This means that in a reliably Democratic district, if Black voters' preferred candidate wins the Democratic primary, that candidate is highly likely to win the general election as well, regardless of any racially polarized voting patterns in the primary.

To assess whether or not a district in Michigan provides Black voters the opportunity to elect a candidate of choice, the district must both be a reliably Democratic district and one in which Black voters are expected to comprise a majority of the Democratic primary electorate. To perform these estimates we use precinct-level election data from the 2016 US presidential and 2018 US Senate elections in Michigan. $\underline{30}$ Quantitative results differ slightly depending on whether one uses data from the presidential or senate elections, though the results remain very similar. In this section we present results that made use of the presidential election data, and present the corresponding results for the senate election case in a brief appendix. (See Figure 5 , Figure 6, and Figure 7.) 


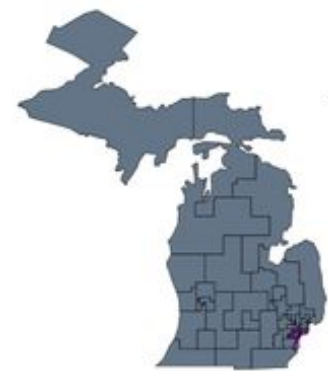

a. Enacted

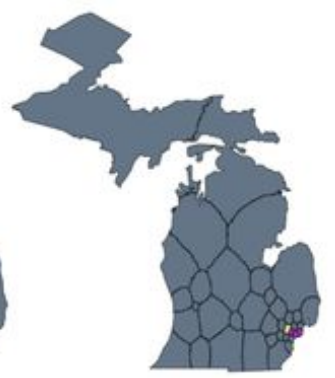

b. Annealing

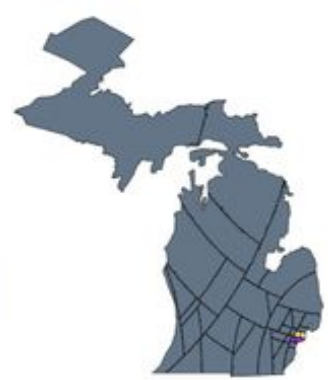

c. Arcs

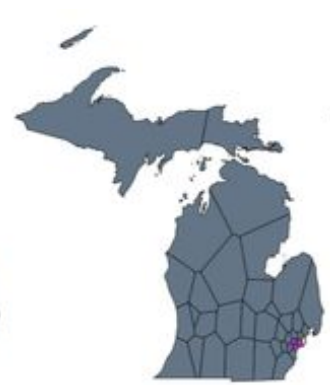

d. Voronoi

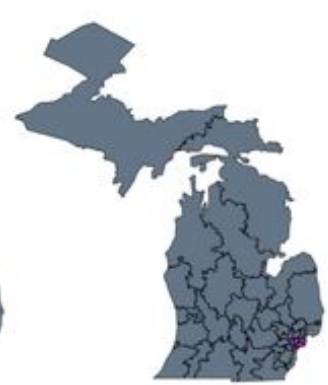

e. Tree

Figure 5

The enacted state senate districts in Michigan and the four algorithmically generated plans. Pink districts have at least 55 percent expected support for the

Black-preferred candidate; yellow districts have between 50 and 55 percent expected support. (a) The currently enacted state senate districts as of 2020. (b) Output from the "Annealing" algorithm. (c) Output from the "Arcs" algorithm. (d)

Output from the "Voronoi" algorithm. (e) Output from the "Tree" algorithm.

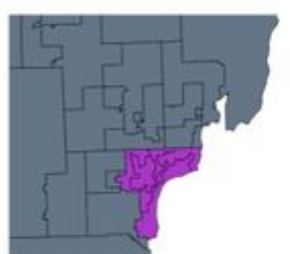

a. Enacted

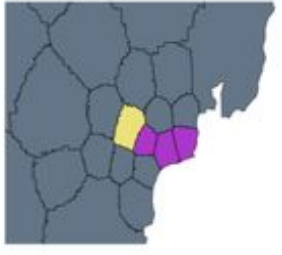

b. Annealing

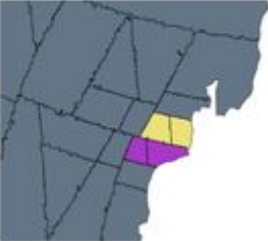

c. Arcs

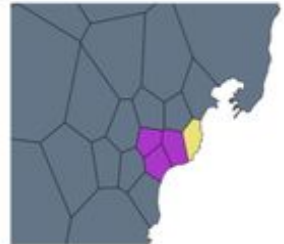

d. Voronoi

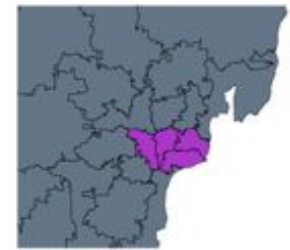

e. Tree

Figure 6

Insets of the Detroit region for the plans shown in figure 5. (a) The currently enacted state senate districts as of 2020. (b) Output from the "Annealing" algorithm. (c) Output from the "Arcs" algorithm. (d) Output from the "Voronoi" algorithm. (e) Output from the "Tree" algorithm. 


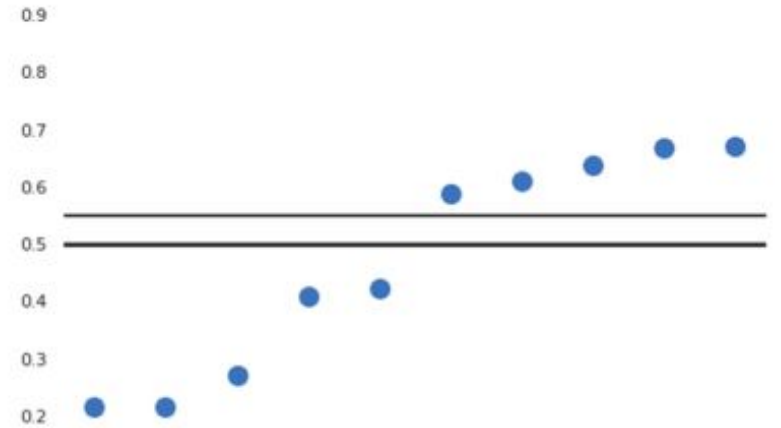

a. Enacted

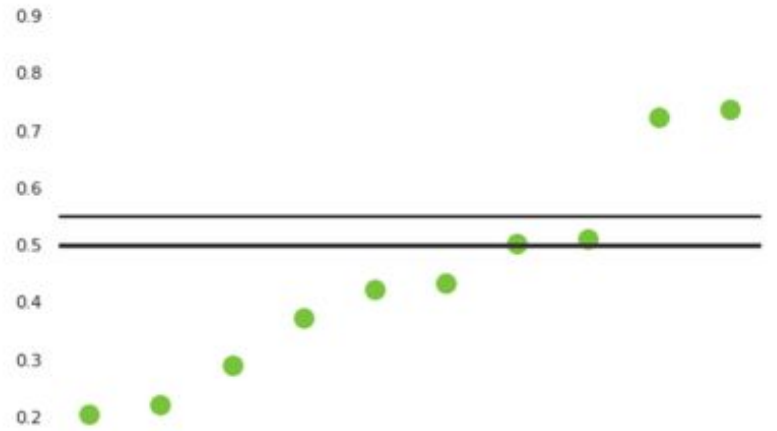

c. Arcs

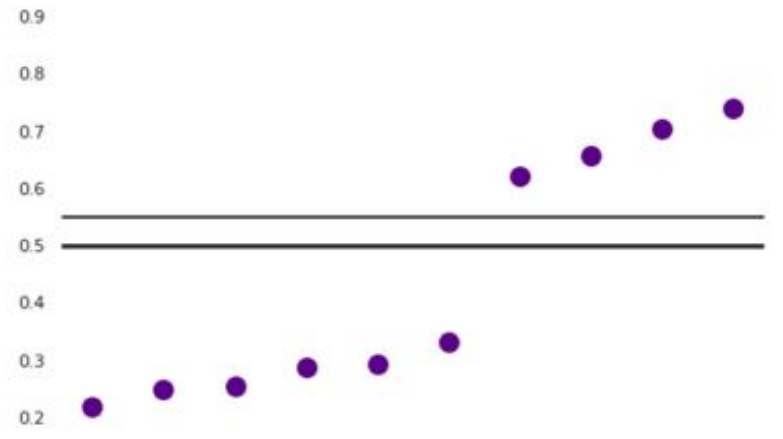

e. Tree

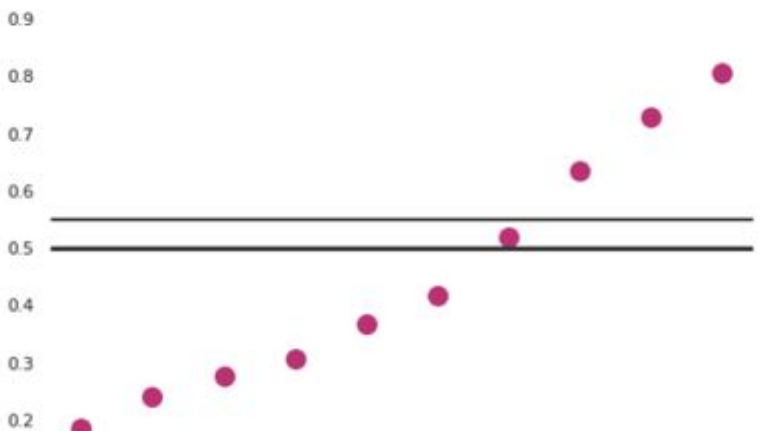

b. Annealing

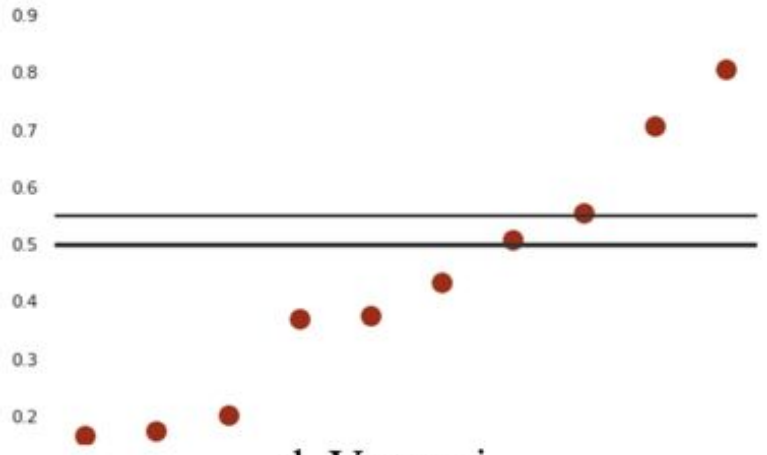

d. Voronoi

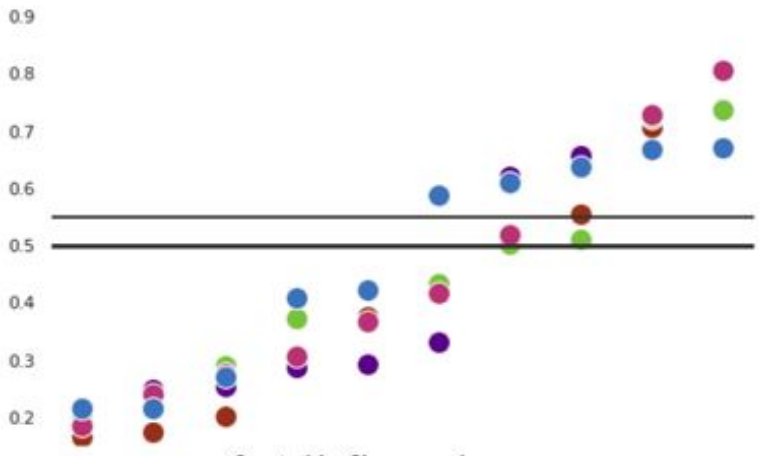

f. All five plans

Figure 7

Plots of the expected support for the Black-preferred candidate in the 10 Michigan districts that have the largest Black populations. Sorted districts appear along the horizontal axis, and expected fraction of votes for the Black-preferred candidate appears along the vertical axis. (a) The currently enacted state senate districts as of 2020. (b) Output from the "Annealing" algorithm. (c) Output from the "Arcs" algorithm. (d) Output from the "Voronoi" algorithm. (e) Output from the "Tree" algorithm. (f) All five plots superimposed.

The enacted plan for Michigan (Figure 5a, Figure 6a, and Figure 7a) contains five districts that meet the criteria of being considered Black opportunity districts. All five 
of these are anchored in the city of Detroit in the southeast part of the state, where the majority of Michigan's Black residents live. Furthermore, all five are overwhelmingly Democratic and all have elected a Black state senator in recent years, although only three of the five districts are majority Black. Given that Michigan's population is approximately 12 percent Black, a standard of proportionality would prioritize four or five Black opportunity districts. The four algorithmically generated plans underrepresent Black voters relative both to the outcomes of the enacted plan and the standard of proportionality.

The Annealing (Figure 5b, Figure 6b, and Figure 7b) and Voronoi (Figure 5c, Figure $\underline{6} \mathrm{c}$, and Figure 7c) plans each include three clear Black opportunity districts and one more district in which Black voters barely constitute a majority of the expected Democratic primary electorate. The Arcs plan (Figure 5 d, Figure 6d, and Figure 7d) includes two clear opportunity districts and two more with a bare majority. The Tree plan (Figure 5e, Figure 6e, and Figure 7e) comes closest to the enacted plan, with four clear Black opportunity districts.

Similar to Alabama, some of the plots in Figure 7 show a steady decline in Black voting strength when stepping through the districts (from right to left). Also like the case for Alabama, the algorithms each draw high-concentration districts (in which the number of Black voters dramatically exceeds the number required to elect candidates of choice) and low-concentration districts (in which the number of Black voters is clearly insufficient to elect candidates of choice). Compared to the enacted plan as well as the proportionality benchmark, each of these algorithms yields fewer Black opportunity districts. $\underline{31}$

\section{Discussion}

As in other domains of public life, some advocates have suggested that computer algorithms should replace human decision-making for consequential activities like determining maps of electoral districts, much as Vickrey proposed back in 1961. Would entrusting such important tasks to algorithms actually produce more fair results? The analysis presented here suggests that we should be skeptical of claims that fair outcomes for redistricting will follow from algorithms that do not take variables such as race or ethnicity into account. On the contrary, as demonstrated here, recently proposed algorithms would each yield severely detrimental outcomes for the political influence of groups that are already marginalized. 
Other advocates have proposed that algorithms could be used in redistricting to inform human decision makers about what may be "possible" or "typical" electoral maps. For example, in the relatively new area of ensemble analysis, an algorithm is used to draft hundreds or thousands of districting plans; a human analyst can then evaluate the ensemble of outputs and ask questions such as, "What is the average number of districts won by Republicans across all the plans?" Yet close study has found that such a procedure may generate plans that-even on average and in the aggregateunderrepresent minority racial and ethnic groups relative to currently enacted plans as well as standards of proportionality. $\underline{32}$ The concern would then be that such algorithms could legitimize unfair or discriminatory decision-making. One could imagine a legislature intent on suppressing Black voters' political strength appealing to a "neutral" algorithm that drew ten million plans, none of which included more than one Black district, as a way to justify a plan that underrepresented Black voters. Such a scenario is not merely hypothetical: a federal judge advocated for exactly this type of analysis to be used as a baseline in legal contexts, which prompted the recent scrutiny of possible ramifications of such procedures. $\underline{33}$

It is certainly not the case that algorithms and computerized map-making are irredeemably useless or harmful for the process of redistricting. Rather, the harms stem from human decision makers giving too much deference to the algorithms' outputs. In principle, a more deliberate approach to the human-computer interface could be used to make the redistricting process more transparent, fair, and accessible.

Computers are bad at inferring human values; humans are bad at fully articulating all the features and facets of a districting plan that we consider desirable or undesirable, especially with sufficient precision to be encoded in a computer algorithm. On the other hand, computers are very good at solving mathematical problems and searching for plans that meet particular criteria. Rather than using algorithms to generate plans to enact, legislators, stakeholders, and the public could use algorithmic redistricting tools to explore and understand trade-offs and the frontiers of what is and is not possible to accomplish for a districting plan in a particular jurisdiction. For example, people could use an algorithm to explore whether it is possible to draw a state senate plan in Alabama with ten Black opportunity districts, consider the resulting plan, and then pose further questions based on relevant community feedback, such as whether it is possible to draw ten opportunity districts and keep the city of Tuscaloosa entirely within one district. 
By incorporating algorithms as a component in a looped, iterative process of proposing and refining districting plans, we can leverage the strengths of computational methods: drawing plans much faster than humans can, drawing plans that simultaneously satisfy specific properties, and offering evidence that some constraints are not mutually satisfiable. With algorithms folded into a human-centered process, people would not need to uncritically accept two primary weaknesses of computers: their inability to devise plans that satisfy anything other than their encoded constraints, and their inability to interpret constraints that cannot be phrased mathematically. In this way, algorithms could become a tool as part of an iterated discussion about social and political values, rather than the arbiters of fairness.

\section{Discussion Questions}

1. Computing power and resources have become vastly more accessible in the sixty years since Vickrey's proposal. During the 1960s, computers were the purview of universities, governments, and wealthy businesses. Twenty years ago, state legislatures would have had access to spatialized demographic, socioeconomic, and election data along with GIS software to analyze and manipulate this data, which would have cost an ordinary person tens of thousands of dollars to use in their own work. Today, with powerful computers more widely accessible as well as the time and effort of open source software developers, public advocates, and data scientists, many of those resources can be downloaded onto your personal laptop, and you can begin drawing and analyzing districts within minutes. How do you feel that the rapid changes in technology and data will impact the way redistricting is done, and do you see roles for algorithms in that process?

2. The idea that an algorithm that is unable to see features like race must therefore not be discriminatory along those features is an argument that is not confined to this domain. Examples of other contexts where this arises are so-called "race-blind" college admissions or hiring, algorithmic tools for policing, sentencing, and other criminal justice applications, and loan administration, to name just a few. How do you think such issues should be handled when computational solutions, like automated redistricting, are brought into traditionally noncomputational settings?

3. A commonly proposed reform is to put the power of redistricting in the hands of something like an independent citizens' commission, a body composed of people who live in a particular jurisdiction who draw district boundaries, rather than leaving redistricting in the hands of politicians. Among these three models of district construction (mathematical algorithm, politician-drawn, independent commission), 
what do you see as the pros and cons of each, and how might their respective strengths be used to complement each other and offset weaknesses?

4. What do you believe are the responsibilities of people proposing algorithmic redistricting solutions in light of the evidence presented in this case study, as well as in the article by Chen and Stephanopoulos, that so-called "neutral" algorithms have potentially discriminatory impacts? $\underline{34}$

\section{Appendix: Plots for Michigan That Incorporate Data from the 2018 US Senate Election}

In this appendix, we reproduce the figures from the Michigan analysis using data from the 2018 US Senate election to make inferences about expected election outcomes in the algorithm-drawn districts. In 2016, Hillary Clinton, a Democrat, lost the state of Michigan to Donald Trump, a Republican, by less than one quarter of a percent. In 2018, the Democratic incumbent senator Debbie Stabenow defeated Republican challenger John James by about 6.5 percentage points. Broadly, Stabenow had a weaker performance than Clinton in urban Detroit but a stronger performance in the Detroit suburbs and rural parts of the state. Because of this geographical difference, and particularly because this goes hand-in-hand with an increase in white voters supporting the Democratic candidate during the 2018 senate election compared to the 2016 presidential election, the evaluation of whether or not Black voters constitute a majority of the Democratic electorate in a hypothetical district may be different when using the 2018 Senate election data versus the 2016 presidential election data.

The district boundaries themselves are identical (Figures $\underline{\mathrm{A} 1}$ and $\underline{\mathrm{A} 2}$ ), since the algorithms do not have access to the political data used to perform these analyses, but which districts represent opportunity districts might differ. In particular, two districts in the Arcs plan and one in the Voronoi plan had expected support for the Blackpreferred candidate between 50 and 55 percent with respect to the 2016 presidential election results but fell below 50 percent with respect to the 2018 US Senate election results, due to the minor difference in the candidates' performance (Figure A3). 


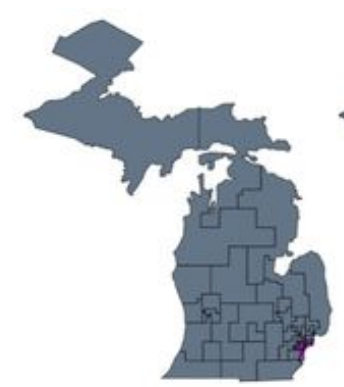

a. Enacted

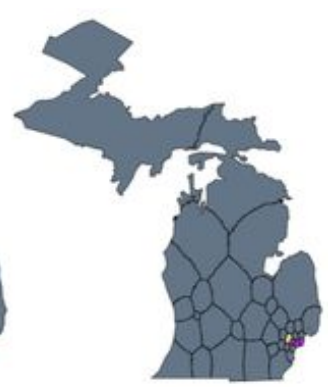

b. Annealing

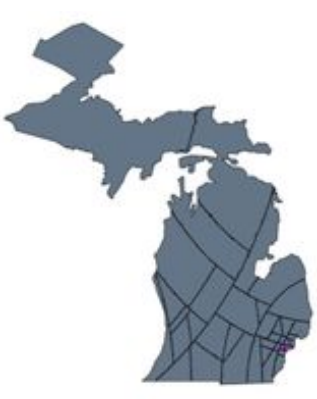

c. Arcs

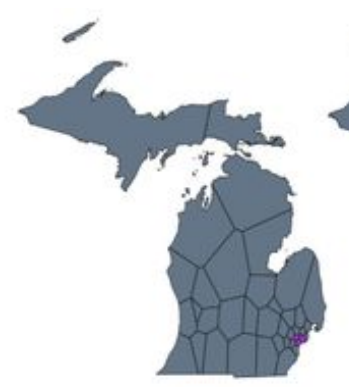

d. Voronoi

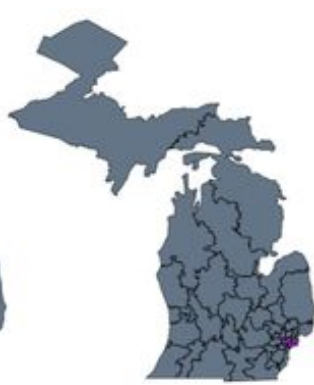

e. Tree

Figure A1

The enacted state senate districts in Michigan and the four algorithmically generated plans. Pink districts have at least 55 percent expected support for the

Black-preferred candidate; yellow districts have between 50 and 55 percent expected support. Estimates of expected support based on data from the 2018 US Senate election. (a) The currently enacted state senate districts as of 2020. (b) Output from the "Annealing" algorithm. (c) Output from the "Arcs" algorithm. (d)

Output from the "Voronoi" algorithm. (e) Output from the "Tree" algorithm.

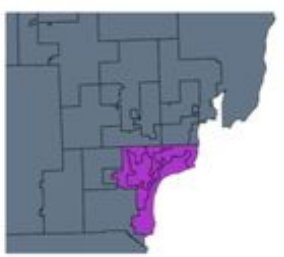

a. Enacted

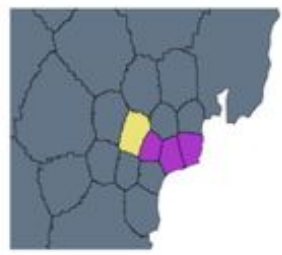

b. Annealing

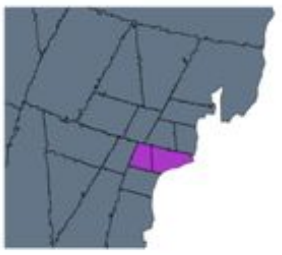

c. Arcs

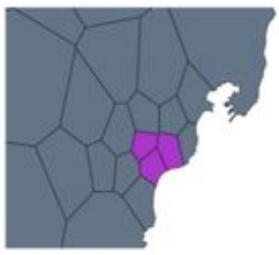

d. Voronoi

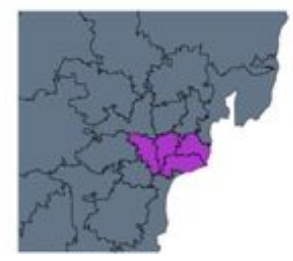

e. Tree

Figure A2

Insets of the Detroit region for the plans shown in Figure A1. (a) The currently enacted state senate districts as of 2020. (b) Output from the "Annealing" algorithm. (c) Output from the "Arcs" algorithm. (d) Output from the "Voronoi" algorithm. (e) Output from the "Tree" algorithm. 


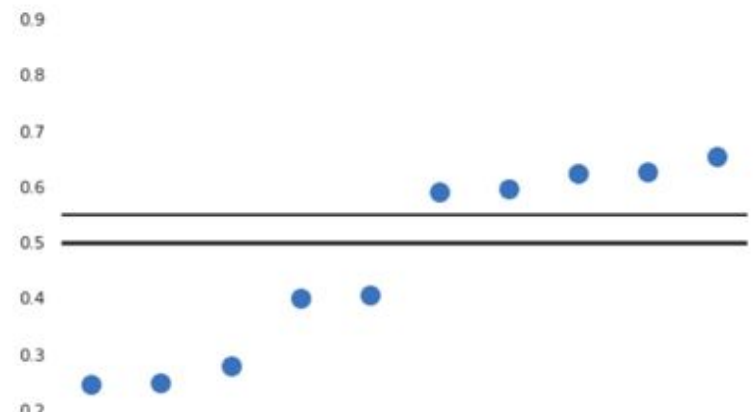

a. Enacted

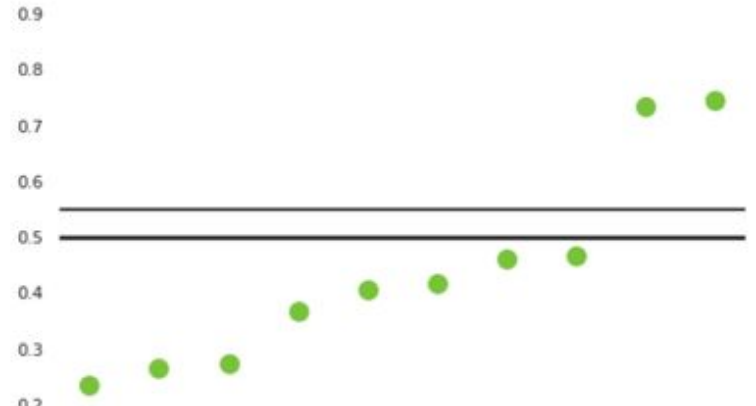

c. Arcs

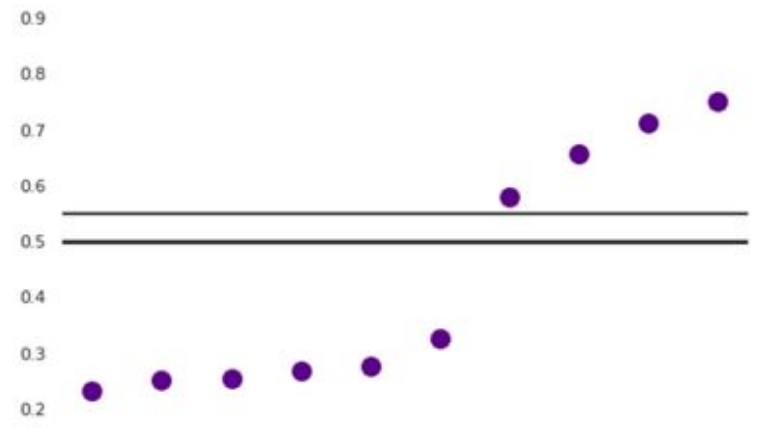

e. Tree

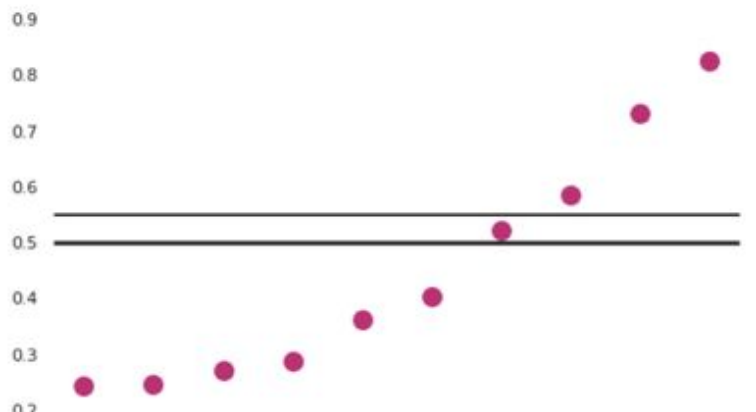

b. Annealing

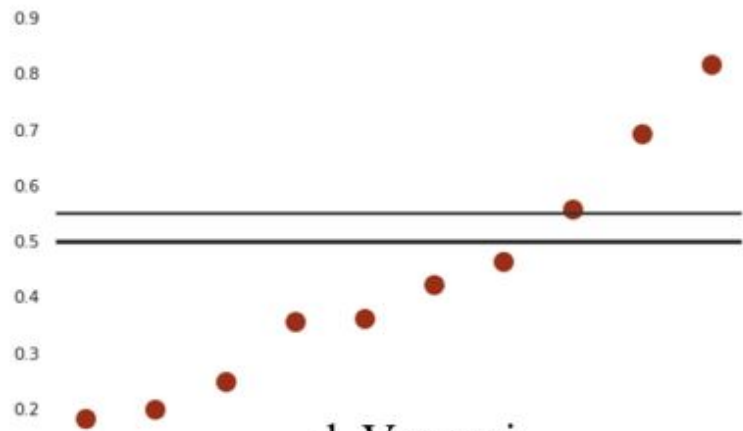

d. Voronoi

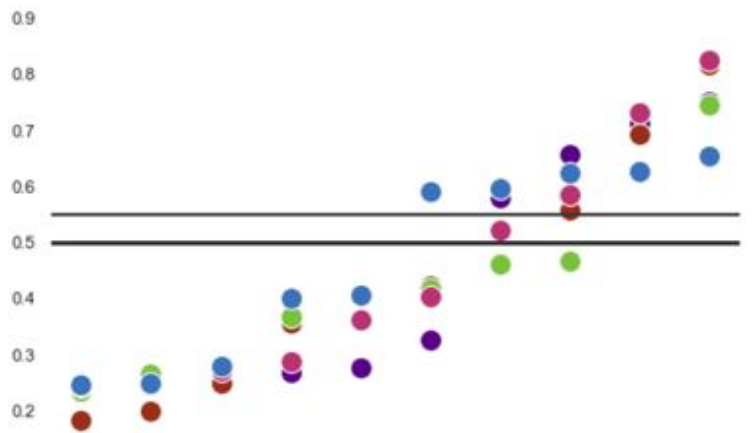

f. All five plans

Figure A3

Plots of the expected support for the Black-preferred candidate in the ten Michigan districts that have the largest Black populations. Estimates of expected support based on data from the 2018 US Senate election. Sorted districts appear along the horizontal axis, and expected fraction of votes for the Black-preferred candidate appears along the vertical axis. (a) The currently enacted state senate districts as of 2020. (b) Output from the "Annealing" algorithm. (c) Output from the "Arcs" algorithm. (d) Output from the "Voronoi" algorithm. (e) Output from the "Tree" algorithm. (f) All five plots superimposed. 


\section{Bibliography}

Anonymous. "Supreme Court: 'Gerrymandering' Pronounced with a Hard 'G.'” Associated Press, July 27, 2018.

https://apnews.com/article/8874fb32cc514f49a5b2aaf1783955f0.

Becker, Amariah, and Justin Solomon. "Redistricting Algorithms." Preprint, submitted November 18, 2020. https://arXiv.org/abs/2011.09504.

Bycoffe, Aaron, Ella Koeze, David Wasserman, and Julia Wolfe. The Atlas of Redistricting. FiveThirtyEight. https://projects.fivethirtyeight.com/redistricting-maps/.

Chen, Jowei, and Nicholas O. Stephanopoulos. "The Race-Blind Future of Voting Rights.” Yale Law Journal 130, no. 4 (February 2021): 862-946.

https://www.yalelawjournal.org/article/the-race-blind-future-of-voting-rights

Cohen-Addad, Vincent, Philip N. Klein, and Neal E. Young. "Balanced Centroidal Power Diagrams for Redistricting." Proceedings of the 26th ACM SIGSPATIAL International Conference on Advances in Geographic Information Systems (2018): 389-96. https://doi.org/10.1145/3274895.3274979.

D’Ignazio, Catherine, and Lauren Klein. "Who Collects the Data? A Tale of Three Maps." MIT Case Studies in Social and Ethical Responsibilities of Computing, Winter 2021. https://doi.org/10.21428/2c646de5.fc6a97cc.

Duchin, Moon, and Douglas M. Spencer. "Models, Race, and the Law." Yale Law Journal 130 (March 2021), 744-97. https://www.yalelawjournal.org/forum/models-race-and-thelaw.

Garfinkel, Simson. "Differential Privacy and the 2020 US Census.” MIT Case Studies in Social and Ethical Responsibilities of Computing, Winter 2022.

https://doi.org/10.21428/2c646de5.7ec6ab93

Ingraham, Christopher. "This Computer Programmer Solved Gerrymandering in His Spare Time." Washington Post, June 3, 2014.

https://www.washingtonpost.com/news/wonk/wp/2014/06/03/this-computerprogrammer-solved-gerrymandering-in-his-spare-time/.

Levin, Harry A., and Sorelle A. Friedler. "Automated Congressional Redistricting." Journal of Experimental Algorithmics 24 (2019): 1-24. https://doi.org/10.1145/3316513. 
Metric Geometry and Gerrymandering Group. “GerryChain.” Open Source Software. https://github.com/mggg/gerrychain.

Olson, Brian. "Impartial Automatic Redistricting." BDistricting. Accessed January 20, 2022. https://bdistricting.com/.

Procaccia, Ariel D., and Jamie Tucker-Foltz. “Compact Redistricting Plans Have Many Spanning Trees." Proceedings of the 2022 Annual ACM-SIAM Symposium on Discrete Algorithms (SODA) (2022): 3754-71, https://doi.org/10.1137/1.9781611977073.148.

Schutzman, Zachary. "Trade-Offs in Fair Redistricting." Proceedings of the AAAI/ACM Conference on AI, Ethics, and Society (2020): 159-65.

https://doi.org/10.1145/3375627.3375802.

Suresh, Harini, and John Guttag. “Understanding Potential Sources of Harm throughout the Machine Learning Life Cycle." MIT Case Studies in Social and Ethical Responsibilities of Computing, Summer 2021.

https://doi.org/10.21428/2c646de5.c16a07bb.

Vickrey, William. “On the Prevention of Gerrymandering.” Political Science Quarterly 76, no. 1 (1961): 105-10. https://doi.org/10.2307/2145973.

Udall, Morris K. “Reapportionment: 'One Man, One Vote' ... That's All She Wrote!,” October 14, 1964. Accessed January 21, 2022.

https://speccoll.library.arizona.edu/onlineexhibits/files/original/11ac559f0063813f0a80bed401b4597f.pdf.

\section{Footnotes}

1. The term "gerrymander" was coined in an 1812 political cartoon comparing the shape of a Massachusetts state senate district, which had allegedly been designed to help then-governor Elbridge Gerry's political party, to that of a salamander. The word "gerrymandering" is typically pronounced with a soft " $g$," as in "gem" or "giant." Gerry's name is correctly pronounced with a hard " $g$," as in "great" or "gold." In 2018, officials from Gerry's hometown of Marblehead, Massachusetts, sent a letter to the Supreme Court requesting that justices pronounce the word with a hard "g." See anon., "Supreme Court: 'Gerrymandering' Pronounced with a Hard 'G,'” Associated Press, July 27, 2018, https://apnews.com/article/8874fb32cc514f49a5b2aaf1783955fo.. 
2. Colgrove v. Green 328 U.S. 549 (1946), https://supreme.justia.com/cases/federal/us/328/549/.

3. In Baker v. Carr, 369 U.S. 186 (1962)

(https://supreme.justia.com/cases/federal/us/369/186/), the Court found redistricting to be a "justiciable" issue under the Equal Protection clause of the Fourteenth Amendment, meaning that districting plans could be found to unconstitutionally violate individuals' rights. In Reynolds v. Sims, 377 U.S. 533 (1964) (https://supreme.justia.com/cases/federal/us/377/533/), the Court held that dramatically differing populations between state legislative districts was an Equal Protection violation, and in Wesberry v. Sanders, 376 U.S. 1 (1964) (https://supreme.justia.com/cases/federal/us/376/1/) found the same for Congressional districts. These cases form the basis for the notion of "one person, one vote.” See Morris K. Udall memorandum, “Reapportionment: 'One Man, One Vote' ... That's All She Wrote!," October 14, 1964, accessed January 21, 2022, https://speccoll.library.arizona.edu/onlineexhibits/files/original/11ac559f0063813f0a80bed401b4597f.pdf.. 4. William Vickrey, "On the Prevention of Gerrymandering," Political Science Quarterly 76, no. 1 (1961): 105-10, https://doi.org/10.2307/2145973. 5. Vickrey, "On the Prevention of Gerrymandering," 106. $\subseteq$ 6. Zachary Schutzman, "Trade-Offs in Fair Redistricting," Proceedings of the AAAI/ACM Conference on AI, Ethics, and Society (2020): 159-65, https://doi.org/10.1145/3375627.3375802.

7. See, e.g., Catherine D’Ignazio and Lauren Klein, "Who Collects the Data? A Tale of Three Maps," MIT Case Studies in Social and Ethical Responsibilities of Computing (Winter 2021), https://doi.org/10.21428/2c646de5.fc6a97cc..

8. Dave Wasserman (@redistrict), tweet, April 21, 2021, https://twitter.com/Redistrict/status/1384853906174394370. Wasserman is a senior editor for the Cook Political Report, specializing on covering the US House of Representatives. $\subseteq$

9. A third type of argument in favor of algorithmic redistricting asserts that any attempt to redress asymmetry or historical injustices via redistricting is itself wrong. That is, proponents argue that there exists some "natural" formation of electoral districts that leads to some particular electoral outcome, and it is wrong for anyone 
to attempt to design districts that deviate from such a formation. Implicitly, advocates for this position make some unfounded assumptions about how redistricting algorithms operate. They either assume that their favorite algorithm is the one that achieves the "natural" districting plan, or that all algorithms result in substantially similar outcomes and therefore the particular implementation is immaterial. This line of reasoning isn't articulated often by experts in the computational domain, and is not an argument we engage with here, but it is nevertheless a common argument in the public discourse. $\subseteq$ 10. See, e.g., Harini Suresh and John Guttag, "Understanding Potential Sources of Harm throughout the Machine Learning Life Cycle," MIT Case Studies in Social and Ethical Responsibilities of Computing (Summer 2021), https://doi.org/10.21428/2c646de5.c16a07bb, and references therein. $\triangleq$ 11. Civil Rights Act of 1957. P.L. 85-315, 71 Stat. 634 (1957), https://www.govinfo.gov/content/pkg/STATUTE-71/pdf/STATUTE-71-Pg634.pdf.. 12. Gomillion v. Lightfoot 364 U.S. 339 (1960), https://supreme.justia.com/cases/federal/us/364/339/. $\leftrightarrows$

13. Voting Rights Act of 1965. P.L. 89-110. 79 Stat. 437 (1965), as amended in 1982, https://www.justice.gov/crt/section-2-voting-rights-act. $\triangleq$

14. Beer v. United States, 425 U.S. 130 (1976),

https://supreme.justia.com/cases/federal/us/425/130/. A key holding in this case was that "retrogression," the implementation of a districting plan that reduced the ability of covered groups (in this case, Black voters in New Orleans) to elect candidates-ofchoice relative to a previously enacted plan, violated Section 5 of the Voting Rights Act. $\doteq$

15. Thornburg v. Gingles, 478 U.S. 30 (1986),

https://supreme.justia.com/cases/federal/us/478/30/. This case is foundational to the ability to challenge a redistricting plan as a racial gerrymander. Plaintiffs must be able to satisfy the three "Gingles criteria" in order to bring a successful racial gerrymandering suit under Section 2 of the Voting Rights Act. These are (1) the racial, ethnic, or language group in question is sufficient in number and lives in a sufficiently geographically compact region that it is feasible to draw a district in which that group constitutes a strict majority; (2) that the group in question votes cohesively; and (3) the group's candidate-of-choice is consistently defeated. Note 
that these conditions are very strong, in particular (1) potentially goes beyond the existence of a feasible opportunity district to the level of requiring the possibility of a "majority-minority" district. Even in a successful suit under these conditions, actually enacting the district or plan that demonstrates (1) is not required. An acceptable remedy may include drawing an opportunity district for the group in question, within which they do not constitute a strict majority. $ヒ$

16. Shaw v. Reno, 509 U.S. 630 (1993)

(https://supreme.justia.com/cases/federal/us/509/630/); Shaw v. Hunt, 517 U.S. 899 (1996) (https://supreme.justia.com/cases/federal/us/517/899/); Hunt v. Cromartie, 526 U.S. 541 (1999) (https://supreme.justia.com/cases/federal/us/526/541/); and Easley v. Cromartie, 532 U.S. 234 (2001) (https://supreme.justia.com/cases/federal/us/532/234/). These cases, out of North Carolina, inform much of the legal boundaries around what is and is not "racial gerrymandering" and how one may prove that racial gerrymandering has occurred. $\subseteq$ 17. Bush v. Vera, 517 U.S. 952 (1996)

(https://supreme.justia.com/cases/federal/us/517/952/). In this case, out of Texas, the Court held that race/ethnicity was the predominant factor in drawing three districts that were ostensibly drawn to allow members of the Black and Hispanic/Latino communities the opportunity to elect candidates of choice. Since those districts could not be shown to support any other reasonable state interest, they were ruled an illegal gerrymander. The districts questioned in this case are extremely irregular in shape, far beyond the level of noncompactness even in today's most bizarrely shaped districts. $\leftrightarrows$

18. For an overview of redistricting algorithms, see the recent survey by Amariah Becker and Justin Solomon, "Redistricting Algorithms," preprint, submitted November 18, 2020, arXiv:2011.09504, as well as the introduction of the paper by Harry A. Levin and Sorelle A. Friedler, "Automated Congressional Redistricting," Journal of Experimental Algorithmics 24 (2019): 1-24, https://doi.org/10.1145/3316513. For broader discussion of the trade-offs between Vickrey's notion of fairness as arising from procedural neutrality and the idea of evaluating the fairness of a districting plan based on the slate of candidates expected to be elected from it, see Schutzman, "Trade-Offs in Fair Redistricting." 19. US Census Bureau, 2010 Decennial Census. $\triangleq$ 
20. On the 2020 US Census, see Simson Garfinkel, "Differential Privacy and the 2020 US Census," MIT Case Studies in Social and Ethical Responsibilities of Computing (Winter 2022).

21. Chestnut v. Merrill, U.S. District Court, Northern District of Alabama, Southern Division, Plaintiffs' Pretrial Brief, October 28, 2019, https://www.brennancenter.org/sites/default/files/2019-11/2019-10-28-

Chestnut\%20v.\%20Merrill-101-Plaintiffs\%27\%20Pre-Trial\%20Brief.pdf.. 22. Spatial and demographic data from Ruth Buck and Metric Geometry and Gerrymandering Group, https://github.com/mggg-states/MI-shapefiles. Election results from Michigan Secretary of State, https://www.michigan.gov/sos. 23. Brian Olson, "Impartial Automatic Redistricting," accessed January 20, 2022, BDistricting, https://bdistricting.com/.

24. Christopher Ingraham, "This Computer Programmer Solved Gerrymandering in His Spare Time," Washington Post, June 3, 2014, https://www.washingtonpost.com/news/wonk/wp/2014/06/03/this-computerprogrammer-solved-gerrymandering-in-his-spare-time/; Aaron Bycoffe et al., The Atlas of Redistricting, FiveThirtyEight, https://projects.fivethirtyeight.com/redistricting-maps/.. 25. Levin and Friedler, "Automated Congressional Redistricting." 26. Vincent Cohen-Addad, Philip N. Klein, and Neal E. Young, "Balanced Centroidal Power Diagrams for Redistricting," Proceedings of the 26th ACM SIGSPATIAL International Conference on Advances in Geographic Information Systems (2018): 389-96, https://doi.org/10.1145/3274895.3274979. 27. Open source software, available at https://github.com/mggg/gerrychain. Developed by the Metric Geometry and Gerrymandering Group. $\_$ 28. Ariel D. Procaccia and Jamie Tucker-Foltz, "Compact Redistricting Plans Have Many Spanning Trees," Proceedings of the 2022 Annual ACM-SIAM Symposium on Discrete Algorithms (SODA) (2022): 3754-71, https://doi.org/10.1137/1.9781611977073.148.. 29. Since measures of compactness are designed to penalize spindly irregularities in districts, and the Tree algorithm disfavors drawing those kinds of districts, we can think of the Tree algorithm as (probabilistically) optimizing for a notion of spanning- 
tree compactness. While different in form from traditional geometric notions of district compactness, spanning-tree compactness has a similar flavor of penalizing or disfavoring bizarre shapes. $\triangleq$

30. Spatial and demographic data from Ruth Buck and Metric Geometry and Gerrymandering Group, mggg-states, https://github.com/mggg-states/MI-shapefiles. Election results from Michigan Secretary of State, https://www.michigan.gov/sos. $\leftrightarrows$ 31. Some of the algorithmic plans contain a gap, with a significant decrease in Black voting strength between one district and the next. Yet these plans still underrepresent Black voters. In the enacted plan, a gap exists between the fifth and sixth districts, where the first five districts are clearly Black opportunity districts and the sixth is not. In the Arcs plan (figure 7b) the gap occurs after the second district, whereas in the Tree plan (figure 7e) the gap occurs after the fourth district. The algorithmically drawn plans in Michigan also each have at least two districts in which Black voters comprise at least 70 percent of the Democratic electorate, which differs from the plans in Alabama, in which only one plan had a single such district. This 70 percent level is clearly much higher than necessary to qualify as an "opportunity district." By overconcentrating Black voters in these districts, the algorithms reduce Black voters' ability to exert influence in neighboring areas, therefore reducing the number of opportunity districts in the plan overall. Concentrating some voting bloc into very few districts to reduce the group's influence elsewhere is called "packing-and-cracking," and, when done intentionally, is a key strategy in partisan and racial gerrymandering. $ヒ$ 32. Jowei Chen and Nicholas O. Stephanopoulos, "The Race-Blind Future of Voting Rights," Yale Law Journal 130, no. 4 (February 2021): 862-946, https://www.yalelawjournal.org/article/the-race-blind-future-of-voting-rights; Moon Duchin and Douglas M. Spencer, "Models, Race, and the Law," Yale Law Journal 130 (March 2021), 744-97, https://www.yalelawjournal.org/forum/models-race-and-thelaw. Chen and Stephanopoulous consider the legal implications of using algorithms to provide a "neutral baseline" of representation along partisan and racial axes. They find that doing so would broadly decrease the ability of Black and Hispanic/Latino communities to exert influence in state legislatures. While our findings are entirely consistent with theirs, we ask a different question and use a different methodology. They compare the use of a single algorithm on a breadth of states, whereas we examine the outputs of several algorithms on only two states. Additionally, their concern is primarily with the average behavior of their algorithm, that is, the 
expected number of districts in which Black voters can elect a candidate of choice, whereas we examine more closely the plans our selection of algorithms draw, that is, the extent to which the algorithms concentrate the power of Black voters in few districts or dilute it across many. $\_$

33. Gonzales v. City of Aurora, No. 02 C 8346 (N.D. Ill. Mar. 13, 2006), https://casetext.com/case/gonzales-v-city-of-aurora. Cf. Chen and Stephanopoulos, "The Race-Blind Future of Voting Rights," and Duchin and Spencer, "Models, Race, and the Law." $\subseteq$

34. Chen and Stephanopoulos, "The Race-Blind Future of Voting Rights." $€$ 